\title{
Qualidade de Vida no Trabalho: o Ambiente Bancário
}

\section{Quality of Life at Work: the Banking Environment}

\author{
Guilherme dos Santos Mazo ${ }^{\mathrm{ab}}$ \\ ${ }^{a}$ Banco do Brasil. SP, Brasil. \\ ${ }^{\mathrm{b}}$ Tribunal de Justiça do Estado de São Paulo, SP. Brasil. \\ E-mail: guilhermemazo@hotmail.com
}

\begin{abstract}
Resumo
A Qualidade de Vida no Trabalho (QVT) tem ganhado importância no ambiente empresarial, visto a necessidade de cuidar da saúde e do bem-estar dos colaboradores em suas atividades laborais. No Brasil, o tema tem se tornado de grande significância, e despertado o interesse dos empresários e gestores. Este trabalho teve o objetivo de analisar as consequências da gestão bancária, baseada na aplicação da QVT e, para isso, foi realizado um levantamento teórico dos aspectos do trabalho que ocasionam problemas e, também, as atitudes que as empresas adotam para contornar a situação. Em função de inúmeras transformações, que acontecem frequentemente, as organizações têm vivenciado constantemente mudanças tecnológicas e econômicas dentro de um mercado extremamente competitivo e as condições de trabalho no ramo bancário repercutiram fortemente na saúde dos trabalhadores do setor. O trabalho ficou marcado como fonte de sofrimento e descontentamento, que levou a situações extremas de estresse. A sobrecarga de trabalho, falta de controle, recompensas insuficientes, falta de coletividade, falta de justiça e conflitos de valores são fatores de desajustes que levam ao estresse no ambiente de trabalho, podendo chegar ao Burnout. A sobrecarga de trabalho também pode ocasionar LER/DORT. Programas de GL e massagem, que muitas organizações adotam, ajudam na prevenção, combate e solução dos problemas gerados pelo trabalho. As políticas de Gestão de Pessoas dos bancos estão sendo voltadas, cada vez mais, para aspetos que envolvam a qualidade de vida dos bancários. As organizações que se preocupam com a qualidade de vida dos trabalhadores expõem e dimensionam suas ações em seus Relatórios Anuais. Pelo que é observado no ambiente bancário, muitos bancos acabam copiando ou fazendo programas similares para não ficarem atrás de seus concorrentes, tanto para reter talentos como para passar uma imagem de boa empresa para a sociedade. De maneira geral, os bancos buscam promover e divulgar a satisfação dos seus colaboradores para agregar valor à empresa e auxiliar no alcance dos objetivos organizacionais.
\end{abstract}

Palavras-chave: QVT. Ambiente Bancário. Estresse. LER/DORT. Gestão de Pessoas.

\begin{abstract}
QVT has gained importance in the business environment, given the need to take care of the employees' health and welfare in their work activities. In Brazil, the theme has become of great significance, and aroused the interest of entrepreneurs and managers. This paper aimed to analyze the consequences of banking management based on the QWL application and for this purpose a theoretical survey was carried out of the work aspects that cause problems and also the attitudes that companies adopt to get around the situation. Due to the numerous transformations that happen frequently, organizations have been constantly experiencing technological and economic changes within an extremely competitive market and working conditions in the banking sector have strongly impacted the workers' health in the sector. The work was marked as a source of suffering and discontent, which led to extreme stress situations. Work overload, lack of control, insufficient rewards, lack of collectivity, lack of justice and conflicts of values are factors of maladjustment that lead to stress in the work environment and can lead to burnout. Work overload can also lead to LER/DORT. GL and massage programs, which many organizations adopt, help to prevent, combat and solve work-related problems. Banks Personnel Management policies are increasingly focused on aspects involving the banking workers' quality of life. Organizations that care about workers' quality of life expose and scale their actions in their Annual Reports. From what is observed in the banking environment, many banks end up copying or making similar programs so as not to fall behind their competitors, both to retain talent and to convey a good company image to society. In general, banks seek to promote and publicize the their employees'satisfaction to add value to the company and assist in achieving organizational goals.
\end{abstract}

Keywords: QVT. Banking Environment. Stress. LER/DORT. People Management.

\section{Introdução}

A vida contemporânea está cada vez mais dinâmica, em função dos efeitos da globalização, o ritmo das atividades se tornou intenso quando se compara a algumas décadas atrás e, consequentemente, aconteceu a mesma coisa com o trabalho.

Em função da cultura que o indivíduo está inserido, não se pergunta mais sobre a questão de existência, ou seja, quem é tal pessoa e sim o que é ou o que faz determinado indivíduo no meio profissional. É dado um elevado valor ao trabalho exercido, que consiste em uma forma de realização individual e social.

Muitas organizações demonstram preocupação com o assunto, embora há algumas que se preocupam com isso somente para transparecer uma boa imagem para a sociedade e tirarem proveito econômico. São recorrentes as situações nas quais os profissionais aceitam conviver em um ambiente organizacional que os prejudiquem.

A QVT (Qualidade de Vida no Trabalho) tem ganhado 
importância no ambiente empresarial, visto a necessidade de cuidar da saúde e do bem-estar dos colaboradores em suas atividades laborais. No Brasil, o tema tem se tornado de grande significância, e despertado o interesse dos empresários e gestores.

A QVT, no setor bancário, é um tema de importante relevância, pois muito é exigido dos bancários. As pessoas possuem limites de tolerância física e mental, quando se trata do ritmo de serviço e da cobrança por resultados.

Este estudo teve o objetivo de analisar as consequências da gestão bancária baseada na aplicação da QVT, tornando-se indispensável uma política de valorização dos colaboradores para que eles se sintam importantes no desempenho de suas atribuições, mais motivados e dedicados em trabalhar na empresa, assim gerarão melhores resultados.

\section{Desenvolvimento}

\subsection{Metodologia}

Foi realizado um levantamento teórico dos aspectos que ocasionam problemas e que levam ao bem-estar, além dos tipos de programas em QVT que as instituições podem proporcionar aos seus trabalhadores. Também, a forma que isso pode influenciar na fidelização dos clientes internos e, consequentemente, na retenção de talentos para a organização.

\subsection{Qualidade de Vida no Trabalho (QVT)}

QVT é um termo que surgiu na década de 1950, porém foi na década de 1960 que se tornou mais explorado, pois se percebeu que a qualidade de vida corporativa dos funcionários influenciava diretamente em seu rendimento, saúde, bemestar e eficácia. Um funcionário, que trabalha em ambiente harmônico e tem motivação para o trabalho, resulta em mais produtividade. Foi nos anos 1970 que o termo se alastrou e começou a ser colocado em prática nas empresas, principalmente, nas estado-unidenses (MARQUES, 2015).

Algumas características da QVT são abordadas por Chiavenato (2014): a) A assimilação de dois aspectos antagônicos: de um lado a reivindicação dos trabalhadores quanto ao bem-estar e a satisfação no trabalho e, do lado oposto, o interesse das organizações sobre os impactos positivos, que geram produtividade e qualidade; b) o conceito implica em respeito da organização pelos seus colaboradores; c) a QVT está conectada à motivação e à satisfação dos funcionários; d) para a obtenção da satisfação dos clientes externos à organização, é necessário que os clientes internos (colaboradores) estejam satisfeitos, concluindo-se que investir no cliente interno é investir no cliente externo.

De acordo com Veloso, Schirrmeister e LimongiFrança (2007), QVT é compreendida como um instrumento que busca tornar os cargos mais eficientes e satisfatórios, além de aumentar os níveis de motivação e bem-estar dos trabalhadores. Os elementos-chave deste constructo se apoiam em quatro princípios: a) resolução de conflitos; b) reengenharia da organização do trabalho; c) inovação nos sistemas de recompensas: financeiras e não financeiras; d) melhoria no ambiente de trabalho (clima, cultura, ambiente, ergonomia e assistência).

Marques (2015) ainda ressalta que apesar de a organização ser a responsável por grande parte dos fatores, que podem resultar na satisfação dos funcionários, existem determinadas posturas que devem partir dos colaboradores: a) evitar fofocas: todos são profissionais e devem se tratar assim. Estas atitudes podem tornar o clima pesado, o que pode criar rivalidade entre as equipes e prejudicar a empresa; b) ser pontual e cumprir os prazos: honrar a jornada de trabalho no horário estabelecido e cumprir os prazos estipulados para evitar acúmulo de serviço e, assim, não passar uma imagem de irresponsável aos superiores. Ao demonstrar responsabilidade e compromisso, maiores as chances de ser reconhecido e, consequentemente, de se sentir motivado; c) trabalhar em equipe: contar com o apoio dos colegas leva a uma maior eficiência do trabalho, sem contar o benefício que gera ao clima corporativo, pois gera laços de confiança na equipe.

Se a qualidade do trabalho for pobre, essa conduzirá à alienação do funcionário, à insatisfação, à má vontade e ao declínio da produtividade. Qualidade do trabalho elevada leva a um clima de confiança e respeito, as pessoas tendem a ter satisfação na atividade exercida e a gerência tende a reduzir as ações de controle social (CHIAVENATO, 2014).

Chiavenato (2014) cita os três principais modelos de QVT, que podem servir de parâmetros para as organizações: Walton (1973), Hackman e Oldha (1975) e Nadler e Lawler (1983). Um modelo mais recente, derivado dos mais antigos e direcionados ao setor bancário é o proposto por Barcelos e Freitas (2012). A importância destes modelos de medição de QVT mostra que as organizações estão dando valorização ao fator humano que as compõem.

\subsection{Características do Setor Bancário}

O setor bancário brasileiro passou por grandes transformações institucionais e legais durante o século XX. As pesquisas referentes ao sistema bancário nacional mostram que esse sofreu grandes transformações, principalmente, na década de 1990, em que ocorreu a entrada de instituições financeiras estrangeiras e a internacionalização dos bancos brasileiros (METZNER; MATIAS, 2015).

A consolidação do sistema financeiro foi derivada de diversos fatores, como a desregulamentação dos serviços bancários, desenvolvimento de tecnologias da informação e mudanças na estratégia gerencial. Destaca-se a privatização dos bancos estaduais e a adesão ao Acordo de Basileia, que alavancaram esse processo, levando a uma nova configuração no Sistema Financeiro Nacional (SFN), mais enxuto e formado por grandes holdings financeiras (METZNER; MATIAS, 2015).

Metzner e Matias (2015) evidenciaram uma maior 
atenção dos bancos para as necessidades de seus clientes, pela necessidade de serviços cada vez mais personalizados e baseados na confiança. Notou-se, assim, uma mudança no perfil dos profissionais, que precisam estar atualizados e desenvolver habilidades/competências para agregar valor às atividades das corporações. Grisci (2008) relata que a profissão de bancário passa a ser de consultor de serviços financeiros.

Os modelos recentes de gestão implantados no trabalho bancário resultaram em modificações nos relacionamentos, nas organizações, no armazenamento e no processamento de informações, com o objetivo de otimização dos resultados. Dessa forma, os modos de gestão contribuíram para moldar outras formas de trabalhar e viver dos trabalhadores, exigindolhes flexibilidade, adaptabilidade, participação, requalificação profissional constante, autonomia para decisões e condução de bons relacionamentos. Porém, houve também excesso de exposição, disponibilidade total na forma de engajamento subjetivo diante das demandas constantemente mutáveis, vulnerabilidade na ocupação dos lugares organizacionais (GRISCI, 2008).

Em função de inúmeras transformações que acontecem, frequentemente, as empresas têm vivenciado constantemente mudanças tecnológicas e econômicas dentro de um mercado extremamente competitivo. Nesse contexto, a categoria bancária sofreu uma reestruturação, resultando na diminuição das equipes de trabalho, maiores exigências quanto à qualificação, polivalência e flexibilidade. As mudanças que integram o processo de reestruturação produtiva resultaram em aumento da produtividade e lucratividade (SILVA; NAVARRO, 2012). Grisci (2008) afirma que as novas tecnologias da informática trouxeram a possibilidade do aumento da produtividade humana e de recursos disponíveis, exigindo dos sujeitos bancários a incorporação de novos conhecimentos e a incorporação de novos modos de ser, em um ritmo de trabalho incrivelmente veloz.

No período compreendido entre junho de 2015 e junho de 2016, no ambiente dos cinco maiores bancos em atividade no Brasil (Banco do Brasil, Bradesco, Caixa Econômica Federal, Itaú Unibanco e Santander), houve extinção de 13.606 postos de trabalho, queda que é observada desde o ano de 2012. Isso em função do fato de os bancos precisarem se adequar aos cenários de crise que se alastram por todo o Mundo, além da nova onda de inovações tecnológicas no sistema financeiro, baseada no incentivo ao uso do autoatendimento via internet e aplicativos de smartphones. Como já ocorreu no passado, as novas tecnologias referentes aos serviços bancários são intensamente poupadoras de mão de obra e poderão em um futuro próximo levar a uma expressiva redução de empregos neste setor (DIEESE, 2016).

\subsection{Saúde e Segurança no Trabalho}

Os profissionais da área de saúde e segurança no trabalho compõem juntos uma equipe multidisciplinar para tornar os ambientes mais saudáveis e seguros. Deve-se manter o foco nas pessoas, no meio ambiente e no patrimônio. Todos devem se conscientizar de que uma tarefa ou posto de trabalho deve oferecer as condições necessárias para que o trabalhador possa desempenhar suas funções com total segurança para evitar acidentes e doenças ocupacionais (WACHOWICZ, 2012).

No Brasil, em 1934, foi criada o que se conhece, atualmente, por Secretaria de Segurança e Saúde no Trabalho. Porém, foi em 1970 que começou a surgir os primeiros médicos nas empresas. O marco do tema ocorreu em 1978, em que o Ministério do Trabalho, por meio da Portaria $n^{\circ} 3.214$, lançou as 28 NRs (Normas Regulamentadoras) relativas à segurança e à medicina do trabalho. Destaque para a NR 4, que estabelece a obrigatoriedade dos serviços médicos de empresa, conhecido como SESMT (Serviços Especializados em Engenharia de Segurança e em Medicina do Trabalho). Em 1994, o Ministério do Trabalho aprova as atuais versões das normas NR 7 (PCMSO - Programa de Controle Médico e Saúde Ocupacional) e NR 9 (PPRA - Programa de Prevenção de Riscos Ambientais) (idem). O artigo $7^{\circ}$, inciso XXI da Constituição da República Federativa do Brasil de 1988 discorre acerca deum tópico importante, que é sobre a redução de riscos inerentes ao trabalho, por meio de normas de saúde, higiene e segurança (BRASIL, 1988).

Compreende-se que segurança no trabalho é um direito do trabalhador que se destina a proporcionar conforto, ergonomia e segurança. A medicina ocupacional é um campo da saúde interessada em proteger a vida e a integridade do empregado. É obrigação do empregador ter uma equipe cuidando da segurança no trabalho, mas é também uma maneira de assegurar o negócio, pois os funcionários, que trabalham com maior segurança, fazem com que as relações humanas sejam melhoradas, consequentemente, aumentando a produtividade (WACHOWICZ, 2012).

Limongi-França (2008) relata que as práticas organizacionais devem ser realizadas na manutenção de pessoas saudáveis e oferecimento do bem-estar na vertente biopsicossocial (potencialidades biológicas, psicológicas e sociais), tanto em aspectos de recuperação como na proteção e promoção da saúde.

Para Chiavenato (2014), segurança no trabalho é a junção de medidas educacionais, médicas, psicológicas e técnicas utilizadas para prevenir acidentes. Para isso se deve eliminar as condições inseguras do ambiente e instruir as pessoas da implantação de práticas preventivas. Compreende-se que segurança do trabalho está diretamente relacionada com as condições de trabalho seguras e saudáveis para os trabalhadores.

As condições de trabalho, no ramo bancário, repercutiram fortemente na saúde dos trabalhadores do setor. O trabalho ficou marcado como fonte de sofrimento e descontentamento, que levou a situações extremas de estresse. Casos de LER/ DORT (Lesões por Esforços Repetitivos e/ou Distúrbios Osteomusculares Relacionados ao Trabalho), doença 
estreitamente relacionada à intensificação do trabalho, também não tardaram a aparecer com a intensificação do ritmo de trabalho, sobrecargas de tarefas, de redução de vagas e de pressão sobre os trabalhadores (SILVA; NAVARRO, 2012).

\subsection{Estresse e Síndrome de Burnout}

O estresse é um processo temporário de adaptação que compreende modificações físicas e mentais. A palavra estresse teve uma elevada difusão, que acabou se transformando em sinônimo de qualquer tipo de alteração sentida pelo indivíduo, na maior partes das vezes negativas. Entretanto, o estresse tem a função de ajustar a homeostase e de melhorar a capacidade do indivíduo para garantir-lhe a sobrevivência, ou seja, pode ter aspectos benignos (PEREIRA, 2014).

O que, na verdade, pode se caracterizar de forma negativa ao indivíduo é a necessidade de adaptação que acarreta. As subdivisões desses estressores são: estressores físicos (provenientes do ambiente externo, tais como ruídos, frio ou calor intenso, fome, dor e que interferem diretamente no corpo do indivíduo); estressores cognitivos (ameaçadores da integridade do indivíduo ou a seu patrimônio, o medo ou a vivência de um assalto, discussões, processos seletivos, entre outros); estressores emocionais (sentimento de perda, de ira, de medo, entre outros) (PEREIRA, 2014).

A sobrecarga de trabalho, a falta de controle, as recompensas insuficientes, a falta de coletividade, a falta de justiça e o conflito de valores são fatores de desajustes que levam ao estresse no ambiente de trabalho. Quando esses fatores extrapolam a capacidade psicológica do indivíduo de suportá-los é desencadeado o burnout (FERREIRA; MENDONÇA, 2012).

Burnout é uma expressão da língua inglesa que significa se queimar ou se destruir pelo fogo. Quando utilizada no contexto laboral, transmite a ideia de ser consumido pelo trabalho. No Brasil, o burnout é reconhecido como uma doença relacionada ao trabalho, sendo identificado como uma sensação de estar acabado. As pessoas apresentam sintoma de fadiga, de cansaço constante, distúrbios no sono, dores musculares e na cabeça, irritabilidade, alterações de humor e de memória, dificuldade de concentração, depressão e perda de iniciativa (idem).

O burnout é um processo que ocorre em resposta à cronificação do estresse ocupacional, trazendo consigo consequências negativas tanto em nível individual, profissional, familiar e social. No âmbito organizacional, os efeitos do burnout são: diminuição da produtividade, pior qualidade do trabalho apresentado, aumento do absenteísmo, alta rotatividade e aumento de acidentes ocupacionais. A pessoa tende a adoecer mais, porque o sistema imunológico fica comprometido. Há casos de pessoas que saíram de férias, descansaram e estavam bem, mas, ao voltar ao trabalho, apresentaram os sintomas novamente. Isso acaba prejudicando a imagem da empresa e leva a prejuízos financeiros (PEREIRA, 2014).
Diferentemente do estresse ocupacional, o burnout sempre tem caráter negativo, apresenta uma dimensão social e interrelacional, que se manifesta por despersonalização e representa um colapso no processo de adaptação, acompanhado de um mau funcionamento crônico no trabalho. Com as mudanças no mundo do trabalho e na natureza do emprego, o burnout atingiu diversos grupos profissionais, entre esses os de prestação de serviços e de funções administrativas como é o caso dos bancários (FERREIRA; MENDONÇA, 2012).

\subsection{LER/DORT e Lombalgias}

Mais conhecidos pela sigla DORT, foram inicialmente denominados por LER, em função do aumento da velocidade e repetição dos movimentos executados durante o trabalho. Ocorrem, principalmente, nos membros superiores e teve um elevado aumento nos últimos anos no ambiente ocupacional. No início, o funcionário com DORT tem uma diminuição do desempenho no trabalho decorrente da dor e fadiga. Esse distúrbio é bem comentado nas redes de comunicação, pois afeta classes sociais mais privilegiadas, como trabalhadores de escritórios e de bancos (MENDES; LEITE, 2012).

Os sintomas mais frequentes são: dor, fadiga, perda de força, dormência e perda gradativa de sensibilidade. Os DORT causam prejuízos individuais e coletivos incalculáveis no ambiente de trabalho. A prevenção e o controle dessas doenças devem estar determinados na organização ergonômica e na preparação muscular para a atividade que se executa. A implantação da ginástica laboral e o incentivo à prática de atividades físicas são um ótimo exemplo de controle (MENDES; LEITE, 2012).

A ergonomia vem concentrando esforços para evitar atividades altamente repetitivas, como forma preventiva de LER/DORT. O balanceamento de atividades, visando tornar seus ciclos adequados às características físicas e psíquicas dos indivíduos é de grande importância para a saúde e a produtividade humana. É necessário implantar um ritmo adequado, carga de trabalho leal, duração da atividade condizente com a demanda, dar autonomia ao funcionário e ter pausas programadas para o descanso. A falta de conhecimento dos gestores pode trazer prejuízos para a organização, pois se aplicados os conhecimentos científicos adequados às atividades da empresa, há um incremento de eficiência na produção e um melhor bem-estar do funcionário (WACHOWICZ, 2012).

Mendes e Leite (2012) relatam que as dores lombares apresentam uma prevalência de $80 \%$ da população em alguma etapa da vida. A lombalgia é a causa mais frequente de diminuição da capacidade no trabalho, de forma temporária e permanente, com as licenças mais longas do INSS, e está em segundo lugar nos afastamentos de trabalho. Diversos estudos têm concluído que o estresse imposto pelas extensas horas de trabalho, comumente posturas e mobílias inadequadas, além dos movimentos repetitivos, em algumas profissões, resultam em alta prevalência de lombalgia e problemas posturais em 
trabalhadores (CANDOTTI et al., 2011).

As medidas preventivas para os trabalhadores são: informações relevantes, ergonomia aplicada na postura em casa e no trabalho, conscientização dos problemas de postura, diminuição das tarefas únicas, aumento da rotatividade das tarefas, descanso durante a jornada e pausa para a implantação de atividade física com o objetivo de quebrar o ritmo de execução das tarefas, por meio de atividades que levem à redução da fadiga e do estresse. Além de medidas preventivas durante o expediente, os trabalhadores devem ser incentivados à realização de atividades físicas fora do ambiente de trabalho, para o preparo da musculatura, aumento da capacidade aeróbica e redução do estresse (MENDES; LEITE, 2012).

\subsection{Ginástica Laboral}

A GL (Ginástica Laboral) é um programa de QVT, em que há promoção de saúde e lazer durante o expediente de trabalho e é também considerada programa de ergonomia, que utiliza atividades físicas planejadas visando prevenção de LER/ DORT. A GL busca criar um espaço em que os trabalhadores exerçam diversas atividades e exercícios físicos, que vão além de um condicionamento mecânico, repetitivo e autômato. A GL deve ser muito bem planejada e dinâmica, pois se trata de uma pausa ativa no trabalho e serve para quebrar o ritmo da tarefa, funcionando como quebra da monotonia. Os objetivos da GL estão envolvidos na prevenção e em auxiliar na reabilitação de doenças que o trabalho repetitivo, monótono e estressante pode acarretar aos trabalhadores (MENDES; LEITE, 2012).

O processo de envelhecimento e exposição continuada a rotinas profissionais e posturais inadequadas possuem forte impacto sobre a incidência das patologias posturais e dores. As pesquisas demonstraram que a GL é eficaz na diminuição da intensidade e frequência da dor, além da correção de hábitos posturais durante o trabalho. É uma ferramenta capaz de produzir efeitos positivos sobre a dor nas costas de trabalhadores, que trabalham por longos períodos na posição sentada. Os programas de prevenção estão em plena expansão dentro das empresas, em que se busca uma melhor qualidade de vida dos trabalhadores e a diminuição de custos, principalmente, com o adoecimento das pessoas. Embora a organização lucre com a redução por ausências de trabalhadores e aumento da produtividade, o trabalhador acaba sendo o mais beneficiado da atividade preventiva de GL. Benefícios secundários como o aumento da integração entre os trabalhadores e uma melhoria da vida social (redução de conflitos interpessoais, incremento da concentração e facilidade para trabalhar em equipe) também ocorrem (CANDOTTI et al., 2011).

\subsection{Massagem}

A massagem tem por objetivo relaxar os músculos tensos, aumentar a amplitude de movimento das articulações, aliviar o estresse e melhorar a circulação. Desde a ansiedade até dores de cabeça tensionais, a massagem oferece um alívio para essas situações, tais como: ansiedade e estresse; síndrome do túnel do carpo; dor crônica nas costas; depressão; fibromialgia; insônia; dor lombar; dor no ombro; dor de cabeça tensional. Em geral, a prática de massagem estimula a saúde e o bemestar geral, melhorando o funcionamento da mente e do corpo (ELLSWORTH; ALTMAN, 2012).

Suguinoshita, Silva e Costa (2013) fizeram um trabalho com uma agência bancária que aplica um programa de Quick Massage para seus funcionários, sendo uma das ferramentas mais eficientes dos programas de QVT, desde que seja realizado com critérios rígidos e foco em resultados. Tratase de uma massagem com duração média de 15 minutos, realizada em uma cadeira projetada para ocupar pouco espaço e mantendo o paciente em posição semelhante à fetal, dando o máximo de conforto possível. Com a correta aplicação da técnica, o paciente sentirá um alívio imediato das dores, relaxamento físico e mental, redução do estresse, além da melhoria na circulação sanguínea.

Entre os trabalhadores pesquisados, todos utilizam o programa, de forma frequente, o que mostra a alta adesão ao programa. Além disso, mais de $70 \%$ dos funcionários avaliaram o programa como ótimo ou bom, o que indica que a massagem está gerando benefícios, mesmo que superficialmente, aos funcionários envolvidos. Foi constatado que os funcionários beneficiados por esta técnica estão satisfeitos, mais relaxados fisicamente, apresentam menor nível de estresse e têm mais disposição para o trabalho (SUGUINOSHITA et al., 2013).

\subsection{Gerência em Recursos Humanos}

De acordo com o estudo renomado de Limongi-França (1996), a atitude de gerência em recursos humanos é subdividida em seis fatores: a) fator 1, imagem da empresa, sendo composto pelos indicadores de ausência de burocracia; imagem; rotinas de pessoal; CIPA; riscos PPRA. Esse apresenta uma combinação entre endomarketing e cumprimento legal; b) fator 2, saúde e ética, sendo constituído pelas variáveis de saúde - PCMSO; recrutamento e seleção; ambulatório; vida pessoal; c) fator 3 , desenvolvimento profissional, que é composto pelas variáveis de treinamento e desenvolvimento; avaliação do desempenho; processos e tecnologia; comitês de decisão; d) fator 4, demandas legais, que se Constituem pelos indicadores de SIPAT (Semana Interna de Prevenção de Acidentes de Trabalho); convênios comerciais; convênio médico; e) fator 5, administração de recursos humanos, sendo composto pelos indicadores de camaradagem e clima; carreira; salário; f) fator 6 , reposição de energias, é constituído pelas variáveis de tempo livre e lazer; refeições. Fatores relativos às necessidades biológicas do indivíduo.

Além das pressões internas, há também as pressões externas que fazem com que a organização procure atingir processos internos de excelência, estas pressões advêm da fiscalização, 
sindicatos, instituições certificadoras, clientes, matriz e concorrentes. Com destaque para as pressões exercidas pelas instituições certificadoras (LIMONGI-FRANÇA, 1996).

\subsection{Dimensionamento pelos Bancos}

As políticas de Gestão de Pessoas dos bancos estão sendo voltadas cada vez mais para aspectos que envolvam a qualidade de vida dos bancários. Alguns exemplos de organizações que se preocupam com a qualidade de vida dos trabalhadores estão expostos e dimensionados em seus Relatórios Anuais.

No Banco do Brasil, em seu Relatório Anual 2015, o banco informa que os seus funcionários são avaliados, semestralmente, por um modelo que considera cinco perspectivas: financeira, de clientes, de processos internos, de aprendizado e crescimento, e socioambiental. A empresa possui várias ferramentas para avaliar a implantação de suas políticas, programas e práticas. A GDP (Gestão de Desempenho Profissional por Competências e Resultados) é um exemplo disso, pois a avaliação é realizada na forma de $360^{\circ}$, ou seja, o funcionário avalia tanto os seus pares como seus subordinados e superiores por meio de uma sistemática imparcial. Além de avaliar competências, o modelo também mensura as contribuições individuais nas conquistas de metas. Essa é uma medida que estimula o cumprimento dos objetivos estratégicos, além de contribuir para a valorização do mérito na ascensão profissional (BANCO DO BRASIL, 2016).

Há a promoção da QVT, priorizando e saúde e a segurança, considerando as dimensões biológica, psicológica e social dos indivíduos. O PCMSO do banco vai além das exigências legais e atua na prevenção, detecção precoce, monitoramento e controle de possíveis danos à saúde. Conta-se também com um programa de QVT complementar, que abrange a destinação de espaços e de verbas específicas para programas de qualidade de vida nas dependências e a realização anual da Semana QVT, como comemorações em datas especiais e homenagens a funcionários. Há várias equipes de SESMT espalhados pelo Brasil, que promovem ações de prevenção e apoio, assessoram as CIPAs (Comissões Internas de Prevenção de Acidentes) e os GRUAs (Grupos de Abandonos). Para os funcionários que atendem ao público foi criado o PAVAS (Programa de Assistência a Vítimas de Assalto e Sequestro), que garante assistência médica, psicológica, jurídica e de segurança em caso de alguma eventualidade ocorrida com o funcionário (BANCO DO BRASIL, 2016).

No Itaú Unibanco, em seu Relatório Anual Consolidado 2015, mostra que o banco provê a melhoria contínua das práticas em gestão de pessoas através do acompanhamento frequente de indicadores que dão suporte na adoção das estratégias mais adequadas às necessidades da organização. Entre os dados utilizados, são acompanhados: indicadores de remuneração, satisfação dos colaboradores, engajamento, rotatividade, absenteísmo, desempenho, diversidade, desenvolvimento e carreira (ITAÚ UNIBANCO HOLDING, 2016).
Muitas ações engajadas na qualidade de vida dos trabalhadores são exercidas pela instituição, sendo essas ações e programas focados em educação para a saúde, concebidos no sentido de prevenir doenças e aconselhar a incorporação de um estilo de vida mais saudável e equilibrado. Acabam cobrindo tanto os funcionários quanto seus familiares e até envolvendo as comunidades em torno dos centros administrativos, quando possível. Essas iniciativas incluem: atendimento nutricional, academia, check-up, Política de Apoio às Mães e Gestantes, Programa Saúde da Mulher, 60 dias adicionais de licença maternidade (de acordo com o Programa Empresa Cidadã), jornada de trabalho fiel, férias de acordo com a lei, Programa Fique OK, Vacina da Gripe e Programa de Readaptação Profissional (ITAÚ UNIBANCO HOLDING, 2016).

O Bradesco, em seu Relatório Integrado 2015, expõe que as pessoas são um ativo fundamental no processo de geração de valor. A organização é atenta às questões de atração e retenção de talentos, qualidade de vida dos funcionários, desenvolvimento e crescimento dos profissionais e geração de emprego e renda. Em seu ambiente interno tem sido estabelecido como objetivo estar presente nos principais rankings elaborados por consultorias conceituadas no tema clima organizacional, o que foi conquistado em 2015. Um dos pilares das atitudes em gestão de pessoas é a valorização interna. O ambiente de trabalho é gerido por uma cultura sólida e de grande valorização da carreira, que assegura igualdade nas condições para que os funcionários se desenvolvam e cresçam hierarquicamente. São admitidos, preferencialmente, profissionais que ocupem cargos mais básicos na empresa e que possam, com o apoio do banco, desenvolver-se para assumir posições mais complexas e de maior responsabilidade. Grande parte dos cargos executivos e das funções intermediárias no Bradesco foi preenchida por profissionais que ascenderam na empresa (BANCO BRADESCO, 2016).

Além do equilíbrio entre remuneração e benefícios, a empresa promove iniciativas para melhorar o ambiente de trabalho, em que aumenta o comprometimento e o desempenho dos colaboradores. Um programa interessante é o Viva Bem, pois representa um conjunto de ações que contribuem para o bem-estar dos profissionais. O programa abrange orientações para uma gestação saudável, orientação nutricional e incentivo às práticas esportivas com foco na saúde e na ampliação do conhecimento dos funcionários sobre o tema. Também são firmadas parcerias com academias de ginástica, salões de beleza, entre outras (BANCO BRADESCO, 2016).

$\mathrm{Na}$ Caixa Econômica Federal, por meio de seu Relatório de Sustentabilidade Caixa 2015, a estratégia em gestão de pessoas é voltada ao estímulo de ideias, da excelência operacional, da meritocracia e da disseminação dos valores e da missão da instituição entre os clientes internos. Iniciativas de avaliação de desempenho e programas de aperfeiçoamento, que abrangem o incentivo ao desenvolvimento de competências, o preparo para a aposentadoria, a promoção da diversidade de etnia e de gênero e os cuidados com a saúde. 
A atenção à qualidade de vida e ao fortalecimento do vínculo com os funcionários também se refletem no oferecimento de remuneração e de benefícios atrativos em relação ao mercado brasileiro (CAIXA ECONÔMICA FEDERAL, 2016).

A gestão do clima organizacional na Caixa se baseia no mapeamento periódico da percepção dos trabalhadores com o objetivo de identificar e propor inovações nas práticas organizacionais, que contribuam para a qualificação do ambiente corporativo e social, de forma a elevar a produtividade. Nesse contexto se incluem iniciativas voltadas à melhoria das condições de trabalho, contemplando o suporte material e tecnológico e as políticas de gestão de pessoas, a exemplo da capacitação, avaliação de desempenho, remuneração e benefícios, ações de relacionamento e promoção interna da diversidade (CAIXA ECONÔMICA FEDERAL, 2016).

\section{Conclusão}

O estudo é importante no desenvolvimento da sociedade humana, pois gera a sensação de utilidade para o indivíduo. Condições dignas de trabalho devem ser fornecidas para que os funcionários possam exercer suas atribuições de forma segura e prazerosa. A legislação tem um papel importante nisso, em que contribui na melhoria das condições de trabalho, pois obriga as organizações a manterem rígidas normas e programas que deem dignidade ao ser humano envolvido no contrato de trabalho ali existente.

As relações de conflito entre a organização e as pessoas envolvidas necessitam ser solucionadas, tempestivamente, para se criarem condições melhores de trabalho e de relacionamento, o que melhora os aspectos psicossociais do trabalho, pois contribui com os resultados e no bom desempenho da organização. A prevenção é a melhor estratégia e envolve ações que impedem os estressores de chegarem em situações desastrosas.

O tema qualidade de vida diz respeito à motivação que os indivíduos possuem para trabalharem em um determinado local e a motivação leva à maior produtividade. Encontrar os indicadores que levam ao alcance da motivação é o que toda empresa queria. Para isso, os programas de QVT devem ser pautados na satisfação dos funcionários em realizar suas necessidades pessoais por meio do trabalho, resultante de diversos fatores como ascensão, crescimento pessoal, remuneração, saúde, segurança, entre outros.

Em relação à subjetividade de cada indivíduo se pode perceber formas diferentes de sentimentos, sensações e estímulos. Assim também é com o conceito de qualidade de vida. É comum no mesmo ambiente de trabalho, por exemplo, um funcionário citar que qualidade de vida é estar com a família ou sair com amigos, enquanto outro perceber que ter qualidade de vida é ser reconhecido no trabalho como um bom funcionário ou praticar esportes.

As atividades físicas dentro de ambientes corporativos atuam de forma benéfica para sanar os possíveis efeitos negativos do trabalho e do uso inadequado de tecnologias, que afetam diretamente o corpo humano. Se forem implantadas, de forma planejada, levam à prevenção de doenças ocupacionais.

Os bancários com estilo de vida mais sedentário são mais estressados, ansiosos, agressivos e tensos, em comparação aos ativos. A prática regular de atividade física é um importante fator de redução do estresse. É constatado, em relatos científicos, que os bancários saudáveis são os que geralmente praticam atividades físicas com regularidade, além de fazerem complementação alimentar com vitaminas e uso da homeopatia, manifestam força, resistência muscular, flexibilidade e capacidade neuromuscular para o trabalho. Já os sedentários, geralmente, apresentam problemas de saúde como colesterol alto, pressão alta e utilizam medicamentos continuamente.

Pelo que é observado nos ambientes dos bancos citados neste trabalho, muitos acabam copiando ou fazendo programas similares para não ficarem atrás de seus concorrentes, tanto para reter talentos como para passar uma imagem de boa empresa para a sociedade, que é refletida em diversas pesquisas.

De maneira geral, os bancos buscam promover e divulgar a satisfação dos seus colaboradores para agregar valor à empresa. As condições básicas de QVT são garantidas nas convenções coletivas firmados com os sindicatos. Além dos benefícios tangíveis que esta ação pode trazer para a empresa, como o aumento de produtividade, diminuição de afastamentos e de faltas, há também os benefícios intangíveis como a valorização da empresa junto aos colaboradores e o mercado, atração e retenção de talentos, entre outros.

\section{Referências}

BANCO BRADESCO S.A. Relatório integrado 2015. Osasco, 2016.

BANCO DO BRASIL S.A. Relatório anual 2015. Brasília, 2016.

BARCELOS, M.R.S.; FREITAS, A.L.P. Qualidade de vida no trabalho no setor bancário: uma análise experimental realizada em Campos dos Goytacazes - RJ. GEPROS, v.8, n.1, p.49-65, 2013.

BRASIL. Presidência da República. Constituição da República Federativa do Brasil de 1988, 1988.

CAIXA ECONÔMICA FEDERAL. Relatório de sustentabilidade Caixa 2015. Brasília, 2016.

CANDOTTI, C.T.; STROSCHEIN, R.; NOLL, M. Efeitos da ginástica laboral na dor nas costas e nos hábitos posturais adotados no ambiente de trabalho. RBCE, v.33, n.3, p.699-714, 2011.

CHIAVENATO, I. Gestão de pessoas: o novo papel dos recursos humanos nas organizações. Barueri: Manole, 2014.

DIEESE. Desempenho dos Bancos $1^{\circ}$ Semestre 2016: bancos seguem com lucros elevados, mas reduzem postos de trabalho e agências. Brasília: Rede Bancários - DIEESE, 2016.

ELLSWORTH, A.; ALTMAN, P. Massagem anatomia ilustrada: guia completo de técnicas básicas de massagem. Barueri: Manole, 2012.

FERREIRA, M.C.; MENDONÇA, H. Saúde e bem-estar no 
trabalho: dimensões individuais e culturais. São Paulo: Casa do Psicólogo, 2012.

GRISCI, C.L.I. Trabalho imaterial, controle rizomático e subjetividade no novo paradigma tecnológico. RAE - Eletrônica, v. 7, n. 1, art. 4, 2008.

ITAÚ UNIBANCO HOLDING S.A. Relatório anual consolidado 2015. São Paulo, 2016.

LIMONGI-FRANÇA, A.C. Indicadores empresariais de qualidade de vida no trabalho: esforço empresarial e satisfação dos empregados no ambiente de manufaturas com certificação ISO 9000. São Paulo: Universidade de São Paulo, 1996.

LIMONGI-FRANÇA, A.C. Qualidade de vida no trabalho - QVT: conceitos e práticas nas empresas da sociedade pósindustrial. São Paulo: Atlas, 2008.

MARQUES, J.R. QVT - qualidade de vida no trabalho. 2015. Disponível em: <http://www.ibccoaching.com.br/portal/ rh-gestao-pessoas/qualidade-de-vida-no-trabalho-dicas-econceitos/>. Acesso em: 18 fev. 2020.
MENDES, R.A.; LEITE, N. Ginástica laboral: princípios e aplicações práticas. Barueri: Manole, 2012.

METZNER, T.D.; MATIAS, A.B. O setor bancário brasileiro de 1990 a 2010. Barueri: Manole, 2015.

PEREIRA, A.M.T.B. Burnout: quando o trabalho ameaça o bemestar do trabalhador. São Paulo: Casa do Psicólogo, 2014.

SILVA, J.L.; NAVARRO, V.L. Organização do trabalho e saúde de trabalhadores bancários. RLAE, v.20, n.2, p.1-9, 2012.

SUGUINOSHITA, E.C.C.; SILVA, F.P.; COSTA, S.G. Análise do programa de QVT aplicado em uma agência bancária - quick massage. RASM, v.3, n.1, p.9-32, 2013.

VELOSO, E.F.R.; SCHIRRMEISTER, R.; LIMONGI-FRANÇA, A.C. A influência da qualidade de vida no trabalho em situações de transição profissional: um estudo de caso sobre desligamento voluntário. RAD, v.9, n.1, p.35-58, 2007.

WACHOWICZ, M.C. Segurança, saúde \& ergonomia. Curitiba: InterSaberes, 2012. 